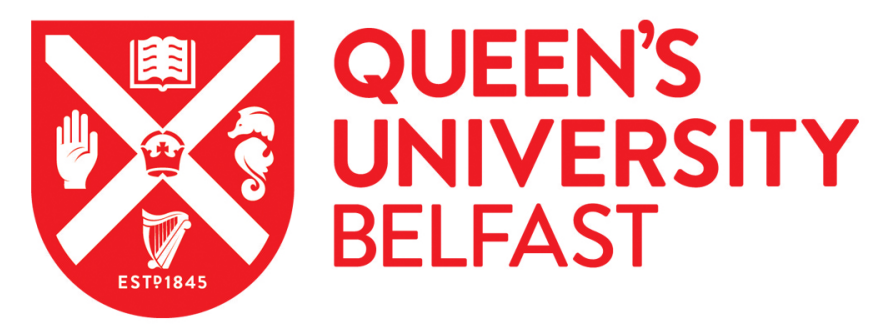

\title{
Efficient Dual-Band Rectifier Using Stepped Impedance Stub Matching Network for Wireless Energy Harvesting
}

Li, S., Cheng, F., Gu, C., Yu, S., \& Huang, K. (2021). Efficient Dual-Band Rectifier Using Stepped Impedance Stub Matching Network for Wireless Energy Harvesting. IEEE Microwave and Wireless Components Letters. https://doi.org/10.1109/LMWC.2021.3078546

Published in:

IEEE Microwave and Wireless Components Letters

Document Version:

Peer reviewed version

Queen's University Belfast - Research Portal:

Link to publication record in Queen's University Belfast Research Portal

Publisher rights

(c) 2021 IEEE.

This work is made available online in accordance with the publisher's policies. Please refer to any applicable terms of use of the publisher.

\section{General rights}

Copyright for the publications made accessible via the Queen's University Belfast Research Portal is retained by the author(s) and / or other copyright owners and it is a condition of accessing these publications that users recognise and abide by the legal requirements associated with these rights.

Take down policy

The Research Portal is Queen's institutional repository that provides access to Queen's research output. Every effort has been made to ensure that content in the Research Portal does not infringe any person's rights, or applicable UK laws. If you discover content in the Research Portal that you believe breaches copyright or violates any law, please contact openaccess@qub.ac.uk. 


\title{
Efficient Dual-band Rectifier Using Stepped Impedance Stub Matching Network for Wireless Energy Harvesting
}

\author{
Shun Li, Fei Cheng, Chao Gu, Sha Yu, and Kama Huang, Senior Member, IEEE
}

\begin{abstract}
This letter presents an efficient dual-band rectifier using stepped impedance stub matching circuit. Theoretical analysis of the dual-band impedance matching circuit comprised of a stepped impedance stub is carried out which plays a key role in designing the resultant dual-band rectifier. The proposed dual-band matching circuit can achieve wide frequency ratio which is analyzed and predicted by simulation. For demonstration, a dual-band rectifier working at 0.915 and $2.45 \mathrm{GHz}$ is fabricated with dimensions of $21.47 \mathrm{~mm} \times 18.93 \mathrm{~mm}$. The measured results show that with a $1500 \Omega$ load, the maximum efficiencies of the rectifier reach $74 \%$ and $73 \%$ at 0.915 and $2.45 \mathrm{GHz}$, respectively. Due to the simple but efficient structure of the dual-band matching network, the dual-band rectifier in this work exhibits merits of compact size and high efficiency.
\end{abstract}

Index Terms-Wireless energy harvesting, dual-band, high efficiency, rectifier, impedance matching, stepped impedance stub.

\section{INTRODUCTION}

$\mathrm{T}$ he wireless energy harvesting technology (WEH) is a promising technology which can power some low power electrical systems including the wireless communication systems and wireless sensor networks without wires [1]-[4]. WEH aims to collect wasted energy from the ambient environment, so it is a promising solution of reducing pollution when employed in battery less low-power sensors. The microwave rectifier is a key component in a wireless energy harvesting system because the conversion from the received microwave power to the usable DC supply is directly affected by the rectifier. In the past years, many single band rectifiers have been proposed for WEH applications [5]-[7]. Compared with a single band rectifier, broadband [8]-[11], dual-band [12]-[22] and multi-band rectifiers [23]-[26] can harvest microwave energy in more bands thus producing more DC energy. Consequently, broad/multi-band rectifiers have attracted growing attentions in recent years.

This work was supported by the National Natural Science Foundation of China under project number 61801317. (Corresponding author: Fei Cheng)

Shun Li, Fei Cheng, Sha Yu and Kama Huang are with College of Electronics and Information Engineering, Sichuan University, Chengdu, 610065, China. (E-mail: chengfei@ scu.edu.cn)

Chao $\mathrm{Gu}$ is with Centre for Wireless Innovation, ECIT Institute, Queens University Belfast, Belfast, BT3 9DT, UK. (E-mail: chao.gu@qub.ac.uk)
The mobile communications and wifi networks usually provide the radiation sources for WEH. Thus, the desired frequencies for dual-band rectifiers are 900, 1800 and $2100 \mathrm{MHz}$ for mobile communications, as well as 915,2450 and 5800 $\mathrm{MHz}$ for ISM band applications. Compared with a dual-band rectifier, the broadband rectifier can cover more bands and harvest more energy. However, it usually has a no more than one octave bandwidth which cannot simultaneously cover 915 and $2450 \mathrm{MHz}$ bands [8]-[11]. The dual-band rectifier can compensate this drawback due to the fact that it is easier to achieve a large frequency ratio including 915/2450 MHz [12]-[14].

The key point for a dual-band rectifier design is the dual-band input matching network. In the previous works, single-stage T-type network [12], two stage T-type networks [16], multi-stub networks [14, 15, 17-20], coupled lines [13], and LC networks $[21,22]$ have been used as the dual-band matching network in the rectifier circuit design. Most of the designs have more than three segments of transmission lines in the matching network which results in large circuit size and complex design [13]-[20]. The LC matching networks can minimize the circuit size [21, 22]. But the low $Q$ capacitors and inductors would lead to higher loss and lower efficiency of the rectifier compared with the transmission line networks.

In this letter, an efficient dual-band rectifier using a stepped impedance stub matching network is proposed for wireless energy harvesting application. The traditional single-stub impedance matching network only can achieve a single band matching performance [7]. In this work, the uniform impedance single-stub is replaced by stepped impedance stub to achieve dual-band performance. We first demonstrate in the simulation that by controlling the impedance and length of the stepped impedance stub matching network, the frequency ratio of the two working frequency bands can be adjusted and large frequency ratio of 3.77 (650 and $2450 \mathrm{MHz}$ ) can be achieved. To verify the design concept, a dual-band rectifier working at 0.915 and $2.45 \mathrm{GHz}$ is fabricated and measured. The resulting rectifier uses only three microstrip lines in the matching network which is less than those in the previous works [13]-[20]. So it releases the design complexity and exhibits compact size. The measured results of the rectifier agree well with the simulated results. The measured $\left|S_{11}\right|$ is better than $-20 \mathrm{~dB}$ at the two operating bands and the peak conversion efficiencies are $74 \%$ and $73 \%$ at 0.915 and $2.45 \mathrm{GHz}$, respectively. 


\section{Design AND ANAlysis of The Dual-BAnd ReCTIFIER}

The block diagram of the proposed dual-band rectifier which works at $f_{1}$ and $f_{2}$ is shown in Fig. 1 . It consists of a single-stub impedance matching network, a Schottky diode, and a DC pass filter. In the single-stub impedance matching network, the shorted stepped impedance stub comprised of TL3 and TL4 can not only achieve dual-band matching, but also provide DC ground for the rectifier. $Z_{i}$ and $\theta_{i}$ represent the characteristic impedance and electrical length of the $i$ th microstrip transmission line at $f_{1}(i=1,2,3,4)$. The single-series topology is chosen here to eliminate the use of an input DC block capacitor required in the single-parallel topology. Thus, the loss of the DC block capacitor can be eliminated to enhance the rectifier efficiency.

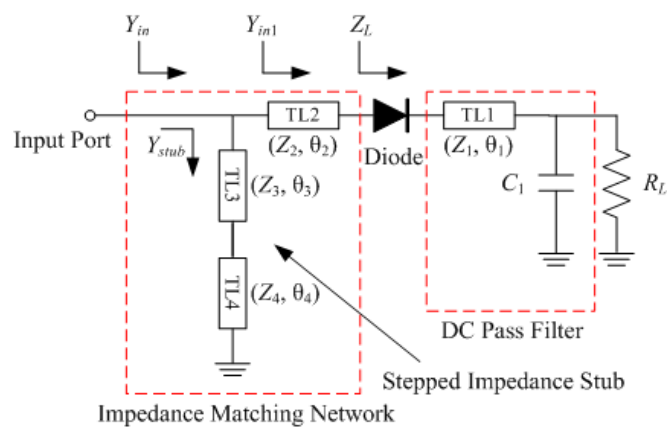

Fig. 1. Schematic of the proposed dual-band rectifier.

A. Analysis of the dual-band matching network

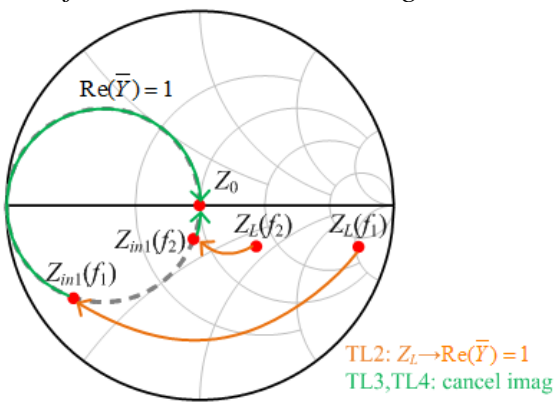

Fig. 2. Design principle of the input matching network.

Fig. 2 shows the design principle of the input matching network of the dual-band rectifier. As the Schottky diode is a nonlinear component whose impedance is a function of input power and frequency, the diode impedances at $f_{1}$ and $f_{2} \mathrm{GHz}$ are quite different. Thus, $Z_{L}$ changes with the frequency. $Z_{L}\left(f_{1}\right)$ and $Z_{L}\left(f_{2}\right)$ are quite different as shown in Fig. 2. To design the dual-band impedance matching network, firstly, $Z_{L}$ is transformed to $Z_{i n 1}$ through a length of series microstrip line TL2. The track of $Z_{L}\left(f_{1}\right.$ and $\left.f_{2}\right)$ moves clockwise. The impedance and electrical length of TL2, $Z_{2}$ and $\theta_{3}$, should satisfy that the real part of normalized $Y_{i n 1}\left(f_{1}\right)$ and $Y_{i n 1}\left(f_{2}\right)$ are equal to 1. As shown in Fig. 2, the two points $Y_{i n 1}\left(f_{1}\right.$ and $\left.f_{2}\right)$ are on the circle of $\operatorname{Re}(\bar{Y})=1$. The shorted stepped impedance stub composed of TL3 and TL4 has an input admittance of

$$
Y_{\text {stub }}\left(f_{i}\right)=-j \frac{Z_{3}-Z_{4} \tan \theta_{4}\left(f_{i}\right) \tan \theta_{3}\left(f_{i}\right)}{Z_{3} Z_{4} \tan \theta_{4}\left(f_{i}\right)+Z_{3}^{2} \tan \theta_{3}\left(f_{i}\right)}, i=1,2
$$

which is a pure imaginary number. By properly design $Z_{3}, Z_{4}, \theta_{3}$ and $\theta_{4}$, the imaginary part of $Y_{i n 1}$ and $Y_{\text {stub }}$ can cancel each other out which makes

$$
\overline{Y_{i n}}\left(f_{i}\right)=\overline{Y_{i n 1}}\left(f_{i}\right)+\overline{Y_{\text {stub }}}\left(f_{i}\right)=1, i=1,2 .
$$

Then, the input impedance of the rectifier is matched at two frequencies.

B. Design of the dual-band rectifiers with different frequency ratios

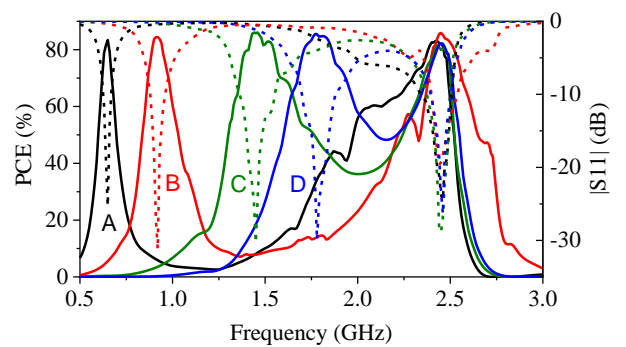

Fig. 3. Simulated $\left|S_{11}\right|$ and PCE versus frequency for dual-band rectifiers of 4 frequency ratios. (Dash line: $\left|S_{11}\right|$, solid line: PCE)

TABLE I

PARAMETERS FOR THE DUAL-BAND RECTIFIERS OF 4 FREQUENCY RATIOS

\begin{tabular}{|c|c|c|c|c|c|c|c|c|}
\hline Model & $Z_{1}$ & $Z_{2}$ & $Z_{3}$ & $Z_{4}$ & $\theta_{1}$ & $\theta_{2}$ & $\theta_{3}$ & $\theta_{4}$ \\
\hline A & 51.9 & 76.1 & 46.1 & 30 & 80.3 & 282.5 & 52.4 & 45.8 \\
\hline B & 94.1 & 97.6 & 39.8 & 85.2 & 66.2 & 188.1 & 37.7 & 22.6 \\
\hline C & 95.7 & 92.4 & 61.2 & 37.7 & 75.9 & 103.1 & 25.5 & 30.7 \\
\hline D & 103.2 & 49.6 & 98.1 & 99.6 & 73.9 & 82.4 & 3.8 & 11.5 \\
\hline
\end{tabular}

Unit: $\Omega$ (characteristic impedance) and degree (electrical length @ $2.45 \mathrm{GHz}$ )

The proposed input impedance matching network design is valid for dual-band operation with different frequency ratios. In order to validate it, dual-band rectifiers with 4 different frequency ratios are simulated in ADS. The higher frequency of the rectifiers is fixed at $2.45 \mathrm{GHz}$ while the lower frequency is adjusted at $0.65,0.915,1.45$, and $1.8 \mathrm{GHz}$ for model $\mathrm{A}, \mathrm{B}, \mathrm{C}$ and $\mathrm{D}$. The corresponding frequency ratios are $3.77,2.68,1.69$, and 1.36, respectively. In the simulation, the Infineon BAT15-03W Schottky diode is used and it has a series resistance of $5 \Omega$ and zero-bias junction capacitance of $138.5 \mathrm{fF}$. The original breakdown voltage of the diode in the datasheet is $4.2 \mathrm{~V}$. In our simulation, it was modified to $8.1 \mathrm{~V}$ to match the measured peak efficiency point. Moreover, $C_{1}=125 \mathrm{pF}$ and $R_{L}$ $=1500 \Omega$. To design the rectifier, firstly, the DC pass filter is designed. TL1 is chosen to have a characteristic impedance of $100 \Omega$ and electrical length of $90^{\circ} @ 2.45 \mathrm{GHz}$ initially. Then, $Z_{L}$ is calculated by

$$
Z_{L}\left(f_{i}\right)=Z_{1} \frac{Z_{d}\left(f_{i}\right) \| j \omega C_{1}+j Z_{1} \tan \theta_{1}\left(f_{i}\right)}{Z_{1}+j\left(Z_{d}\left(f_{i}\right) \| j \omega C\right) \tan \theta_{1}\left(f_{i}\right)}+Z_{d}\left(f_{i}\right), i=1,2
$$

with the diode impedance of [27]

$$
Z_{d}=\frac{\pi R_{s}}{\cos \theta_{\text {on }}\left(\frac{\theta_{o n}}{\cos \theta_{\text {on }}}-\sin \theta_{o n}\right)+j \omega R_{s} C_{j}\left(\frac{\pi-\theta_{\text {on }}}{\cos \theta_{\text {on }}}+\sin \theta_{\text {on }}\right)} \text { (4) }
$$

where $R_{s}$ is the series resistance of the diode, $C_{j}$ is the diode junction capacitance, and $\theta_{\text {on }}$ is the turn on angle of the diode. After that, the input matching network can be gained by the previous analysis. Finally, all the circuit parameters are optimized in ADS. The simulated $\left|S_{11}\right|$ and PCEs (Power Conversion Efficiency) are shown in Fig. 3 and the optimized rectifier parameters are listed in Table I. It can be seen that $\left|S_{11}\right|$ at the working frequencies is always better than $-20 \mathrm{~dB}$ which indi- 
cates a good matching is achieved at the rectifier input port. It ensures that the rectifiers reflect little energy back to the source and most input RF energy goes into the diode. In Fig. 3, the peak PCEs of the rectifiers are better than $80 \%$ at the working frequencies. In general, the proposed matching network can work effectively in the dual-band rectifier design with various frequency ratios.

\section{ImPLEMENTATION AND MEASUREMENT RESULtS}

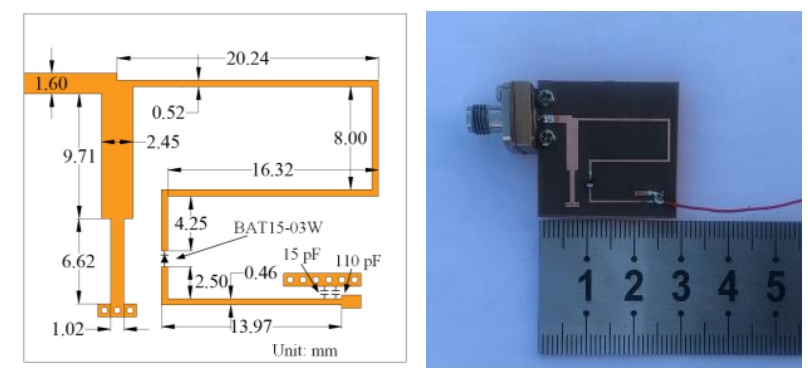

Fig. 4. Layout and photograph of the proposed dual-band rectifier.

The proposed dual-band rectifier at 0.915 and $2.45 \mathrm{GHz}$ is fabricated on a Taconic TLY substrate with a thickness of 0.508 $\mathrm{mm}$, a relative dielectric constant of 2.2, and a loss tangent of 0.0009. The Infineon BAT15-03W Schottky diode is implemented. In addition, two capacitors of 15 and $110 \mathrm{pF}$ are used in the output DC pass filter. Fig. 4 shows the layout and photograph of the fabricated rectifier. A portion of the microstrip line is folded to minimize the circuit size. The dimensions of the rectifier are $21.47 \mathrm{~mm} \times 18.93 \mathrm{~mm}$.

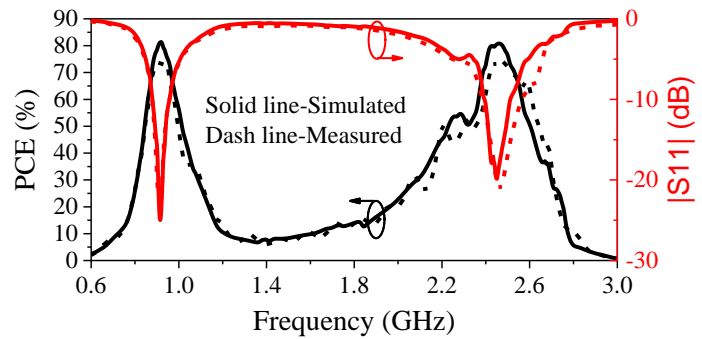

Fig. 5. Simulated and measured $\left|S_{11}\right|$ and PCE versus frequency.

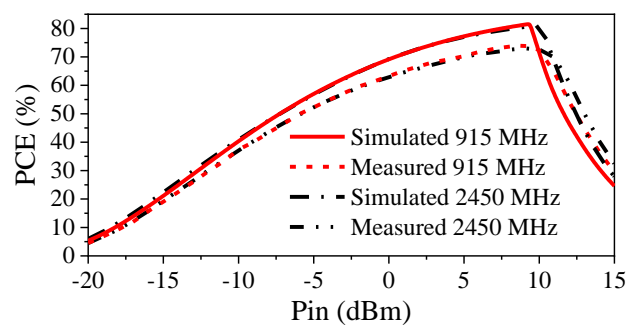

Fig. 6. Simulated and measured PCE versus input power.

Fig. 5 shows the simulated and measured $\left|S_{11}\right|$ and PCE changing with the frequency. The rectifier is working at $9 \mathrm{dBm}$ input power with the load resistance of $1500 \Omega$. The measured and simulated results agree well with each other except that the higher band has a small shift. This may result from the discrepancy of the capacitor and diode model parameters between the simulation predictions and real-world scenarios at high frequencies. The measured $\left|S_{11}\right|$ are -23.34 and $-21.19 \mathrm{~dB}$ at 0.915 and $2.45 \mathrm{GHz}$ respectively while the simulated ones are
-24.98 and $-19.87 \mathrm{~dB}$ at the two frequencies. The measured maximum PCEs are higher than $70 \%$ from 0.89 to $0.95 \mathrm{GHz}$ and 2.42 to $2.51 \mathrm{GHz}$ while the simulated ones are from 0.88 to 0.96 $\mathrm{GHz}$ and 2.39 to $2.53 \mathrm{GHz}$. Fig. 6 shows the simulated and measured PCEs versus the input power at 0.915 and $2.45 \mathrm{GHz}$ with the load resistance of $1500 \Omega$. The measured maximum efficiencies are $74 \%$ and $73 \%$ at 0.915 and $2.45 \mathrm{GHz}$ respectively which are about $8 \%$ lower than the simulated ones. The measured input power ranges for $\mathrm{PCE}>50 \%$ are from -5 to 12 $\mathrm{dBm}$ at $0.915 \mathrm{GHz}$ and -5 to $13 \mathrm{dBm}$ at $2.45 \mathrm{GHz}$, respectively. Table II compares the proposed rectifier in this work with some previously published works. As observed, the proposed rectifier has higher efficiency than most other designs and smallest dimensions except the CMOS rectifier chip in [21]. Additionally, the impedance matching network in our design is simplest with only 3 transmission line segments.

TABLE II

COMPARISON BETWEEN THE PROPOSED RECTIFIER AND THE REFERENCES

\begin{tabular}{|c|c|c|c|c|c|c|}
\hline \multirow[b]{2}{*}{ Ref. } & \multirow{2}{*}{$\begin{array}{c}f_{R F} \\
(\mathrm{GHz})\end{array}$} & \multicolumn{2}{|c|}{ Peak PCE Point } & \multirow{2}{*}{$\begin{array}{c}\text { Size } \\
\left(\mathrm{mm}^{2}\right)\end{array}$} & \multirow[b]{2}{*}{ Diode } & \multirow{2}{*}{$\begin{array}{l}\text { No. } \\
\text { of } \\
\text { TL }\end{array}$} \\
\hline & & $\begin{array}{c}P_{\text {in }} \\
(\mathrm{dBm})\end{array}$ & PCE (\%) & & & \\
\hline \multirow{2}{*}{ [12] } & $\begin{array}{c}0.915 \\
2.45\end{array}$ & 12 & $81.7,73.1$ & $\begin{array}{c}74.1 \times \\
35.3\end{array}$ & $\begin{array}{c}\text { HSMS } \\
2862\end{array}$ & 3 \\
\hline & $\begin{array}{c}0.915, \\
2.45\end{array}$ & -1 & $69.2,64.1$ & $\begin{array}{c}80.3 \times \\
23.4\end{array}$ & $\begin{array}{c}\text { SMS76 } \\
30\end{array}$ & 3 \\
\hline [13] & $\begin{array}{c}0.915 \\
2.45\end{array}$ & 30 & 66,58 & $\begin{array}{l}\text { about } \\
60 \times 79\end{array}$ & $\begin{array}{c}\text { HSMS } \\
2822, \\
\text { HSMS } \\
2852\end{array}$ & 4 \\
\hline [14] & $\begin{array}{c}0.915 \\
2.45 \\
\end{array}$ & 14.6 & $77.2,73.5$ & $\begin{array}{l}\text { about } \\
60 \times 87\end{array}$ & $\begin{array}{c}\text { HSMS } \\
2862\end{array}$ & 5 \\
\hline [15] & $\begin{array}{c}0.915 \\
1.8\end{array}$ & 5 & NA & $37 \times 23$ & $\begin{array}{l}\text { HSMS } \\
2850\end{array}$ & 6 \\
\hline [16] & $\begin{array}{l}1.84, \\
2.14\end{array}$ & -18 & $37.5,34$ & $\begin{array}{c}146 \times 2 \\
6.5\end{array}$ & $\begin{array}{l}\text { HSMS } \\
2852\end{array}$ & 6 \\
\hline [17] & $\begin{array}{c}2.45 \\
5.8\end{array}$ & 11 & $64.8,64.2$ & $\begin{array}{c}48.1 \times \\
40.1\end{array}$ & $\begin{array}{l}\text { HSMS } \\
286\end{array}$ & 4 \\
\hline [18] & $\begin{array}{c}2.45 \\
5.8\end{array}$ & 0 & $\begin{array}{l}57.6, \\
33.62\end{array}$ & $89 \times 34$ & $\begin{array}{c}\text { HSMS } \\
2850\end{array}$ & 6 \\
\hline [20] & $\begin{array}{l}1.8, \\
2.45 \\
\end{array}$ & 9 & 70,68 & $\begin{array}{c}0.25 \\
\lambda_{\mathrm{g}}{ }^{2} \\
\end{array}$ & $\begin{array}{l}\text { HSMS } \\
285 \mathrm{C} \\
\end{array}$ & 7 \\
\hline [21] & $\begin{array}{l}0.93 \\
2.63\end{array}$ & -1 & $25.2,22.5$ & $2.9 \times 4$ & CMOS & LC \\
\hline [22] & $\begin{array}{c}0.915 \\
2.45 \\
\end{array}$ & -15 & 23,18 & NA & $\begin{array}{c}\text { SMS76 } \\
30\end{array}$ & LC \\
\hline $\begin{array}{l}\text { This } \\
\text { work }\end{array}$ & $\begin{array}{c}0.915 \\
2.45\end{array}$ & 9 & 74,73 & $\begin{array}{c}21.5 \\
\times 18.9\end{array}$ & $\begin{array}{l}\text { BAT15 } \\
-03 W \\
\end{array}$ & 3 \\
\hline
\end{tabular}

No. of TL: number of transmission line segments in the input matching circuit

\section{CONCLUSION}

In this letter, an efficient dual-band rectifier using a stepped impedance stub matching network for WEH is presented. The practicality of the proposed topology is demonstrated through the fabrication of a 0.915 and $2.45 \mathrm{GHz}$ dual-band rectifier. At 9 $\mathrm{dBm}$ input power level, the maximum conversion efficiencies are $74 \%$ and $73 \%$ at 0.915 and $2.45 \mathrm{GHz}$, respectively. Compared with other reported dual-band rectifiers, the proposed rectifier has the advantages of large frequency ratio, high efficiency, simple structure, and small dimensions. The rectifier can be used in a WEH system due to the outstanding performance at low input power. 


\section{REFERENCES}

[1] T. Ruan, J. Z. Chew, and M. Zhu, "Energy-aware approaches for energy harvesting powered wireless sensor nodes" IEEE Sensors Journal, vol. 17 no.7, pp. 2165-2173, Apr. 2017.

[2] N. Tung, "Multi-band ambient RF energy harvesting rectifier for autonomous wireless sensor networks" IEEE Region 10 Conference, 2016.

[3] H. Zhang, Y.-X. Guo, Z. Zhong, and W. Wu, "Cooperative integration of RF energy harvesting and dedicated WPT for wireless sensor networks" IEEE Microw. Wireless Compon. Lett., vol. 29, no.4, pp. 291-293, Apr. 2019.

[4] J. Bito, J. G. Hester, and M. M. Tentzeris, "Ambient RF energy harvesting from a two-way talk radio for flexible wearable wireless sensor devices utilizing inkjet printing technologies," IEEE Trans. Microw. Theory Techn., vol. 63, no. 12, pp. 4533-4543, Dec. 2015.

[5] S. Ladan, N. Ghassemi, A. Ghiotto and K. Wu, "Highly Efficient Compact Rectenna for Wireless Energy Harvesting Application," IEEE Microwave Magazine, vol. 14, no. 1, pp. 117-122, Jan.-Feb. 2013.

[6] Yong Huang, N. Shinohara and H. Toromura, "A wideband rectenna for 2.4 GHz-band RF energy harvesting," 2016 IEEE Wireless Power Transfer Conference (WPTC), Aveiro, Portugal, 2016, pp. 1-3.

[7] M. Rajabi, N. Pan, S. Claessens, S. Pollin and D. Schreurs, "Modulation Techniques for Simultaneous Wireless Information and Power Transfer With an Integrated Rectifier-Receiver," IEEE Transactions on Microwave Theory and Techniques, vol. 66, no. 5, pp. 2373-2385, May 2018.

[8] C. Song, Y. Huang, J. Zhou, J. Zhang, S. Yuan and P. Carter, "A High-Efficiency Broadband Rectenna for Ambient Wireless Energy Harvesting," IEEE Transactions on Antennas and Propagation, vol. 63, no. 8, pp. 3486-3495, Aug. 2015.

[9] M. M. Mansour and H. Kanaya, "Compact and Broadband RF Rectifier With 1.5 Octave Bandwidth Based on a Simple Pair of L-Section Matching Network," IEEE Microwave and Wireless Components Letters, vol. 28, no. 4, pp. 335-337, April 2018.

[10] Y. Shi, Y. Fan, Y. Li, L. Yang and M. Wang, "An Efficient Broadband Slotted Rectenna for Wireless Power Transfer at LTE Band," IEEE Transactions on Antennas and Propagation, vol. 67, no. 2, pp. 814-822, Feb. 2019.

[11] W. Liu, K. Huang, T. Wang, Z. Zhang and J. Hou, "A Broadband High-Efficiency RF Rectifier for Ambient RF Energy Harvesting," IEEE Microwave and Wireless Components Letters, vol. 30, no. 12, pp. 1185-1188, Dec. 2020.

[12] J. Liu, M. Huang and Z. Du, "Design of Compact Dual-Band RF Rectifiers for Wireless Power Transfer and Energy Harvesting," IEEE Access, vol. 8, pp. 184901-184908, 2020.

[13] M. Huang, Y. L. Lin, J.-H. Ou, X. Y. Zhang, Q. W. Lin, W. Che, and Q. Xue, "Single- and dual-band RF rectifiers with extended input power range using automatic impedance transforming" IEEE Trans. Microw. Theory Tech., vol. 67, no. 5, pp. 1974-1984, May 2019.

[14] J. Liu, X. Y. Zhang, and C.-L. Yang, "Analysis and design of dual-band rectifier using novel matching network," IEEE Trans. Circuits Syst. II, Exp. Briefs, vol. 65, no. 4, pp. 431-435, Apr. 2018.

[15] Z. Liu, Z. Zheng, and Y.-X. Guo, "Enhanced dual-band ambient RF energy harvesting with ultra-wide power range" IEEE Microw. Wireless Compon. Lett., vol. 25, no. 9, pp. 630-632, Sep. 2015.

[16] H. Sun, Y.-x. Guo, M. He, and Z. Zhong: "A dual-band rectenna using broadband Yagi antenna array for ambient RF power harvesting" IEEE Antennas and Wireless Propa. Lett., vol. 12, pp. 918-921, 2013.

[17] K. Hamano, A. Suzuki, K. Nishikawa and S. Kawasaki, "2.4/5.8GHz Dual-band Rectifiers for Aerospace Wireless Sensor and RF Energy Harvester System," 2019 IEEE Radio and Wireless Symposium (RWS), Orlando, FL, USA, 2019, pp. 1-4.

[18] X. Huang, J. Wang, X. Wu and M. Liu, "A dual-band rectifier for low-power Wireless Power Transmission system," 2015 Asia-Pacific Microwave Conference (APMC), Nanjing, China, 2015, pp. 1-3.

[19] D. Wang and R. Negra, "Design of a dual-band rectifier for wireless power transmission," Proc. IEEE Wireless Power Transf. (WPT), May 2013, pp. 127-130.

[20] S. Chandravanshi and M.J. Akhtar, "An efficient dual-band rectenna using symmetrical rectifying circuit and slotted monopole antenna array," Int J RF Microw Comput.-Aided Eng., vol. 30, 2020, pp. 1- 15.

[21] C.-H. Li, M.-C. Yu, H.-J. Lin, "A compact 0.9-/2.6-GHz dual-band RF energy harvester using SiP technique” IEEE Microw. Wireless Compon. Lett., vol. 27, no. 7, pp. 1754-1762, Jul. 2017.

[22] K. Niotaki, A. Georgiadis, A. Collado, and J. S. Vardakas, "Dual-band resistance compression networks for improved rectifier performance" IEEE Trans. Microw. Theory Tech., vol. 62, no. 12, pp. 3512-3521, Dec. 2014.

[23] V. Kuhn, C. Lahuec, F. Seguin, and C. Person, "A multi-band stacked RF energy harvester with RF-to-DC efficiency up to 84\%" IEEE Trans. Microw. Theory Tech., vol. 26, no. 10, pp. 819-821, May 2015.

[24] J.-J. Lu, X.-X. Yang, H. Mei, and C. Tan, "A four-band rectifier with adaptive power for electromagnetic energy harvesting" IEEE Microw. Wireless Compon. Lett., vol. 29, no. 4, pp. 291-293, Oct. 2016.

[25] C.-Y. Hsu, S.-C. Lin, and Z.-M. Tsai, "Quadband rectifier using resonant matching networks for enhanced harvesting capability" IEEE Microw. Wireless Compon. Lett., vol. 27, no. 7, pp. 669-671, Jul. 2017.

[26] S. Shen, Y. Zhang, C.-Y. Chiu, and R. Murch, “A triple-band high gain multibeam ambient RF energy harvesting system utilizing hybrid combining,', IEEE Trans. Ind. Electron., vol. 67, no. 11, pp. 9215-9226, Nov. 2020.

[27] J. O. McSpadden, L. Fan, and K. Chang, "Design and experiments of a high-conversion-efficiency 5.8-GHz rectenna," IEEE Trans. Microw. Theory Techn., vol. 46, no. 12, pp. 2053-2060, Dec. 1998. 